\title{
Taking effective delay reduction measures and using delay elements as indices for Tokyo's metropolitan railways
}

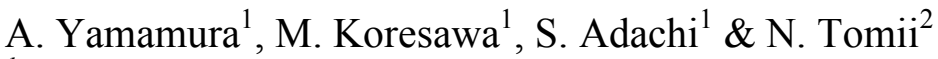 \\ ${ }^{1}$ Tokyo Metro Co. Ltd., Japan \\ ${ }^{2}$ Chiba Institute of Technology, Japan
}

\begin{abstract}
In the Tokyo metropolitan area of Japan, several minutes of delays often happen during morning rush hour. This is because a massive number of passengers use trains for commuting. Then trains and platforms are congested. Above all, once a train delays due to increasing dwell time, the subsequent train has to wait outside a station or slow down if the platform is occupied by the preceding train. This process is repeated over and over again and delays increase more and more. So we had to identify how often or how large delays occur and take delay reduction measures, because it is pointless to blindly carry out delay reduction measures. The measures should be carried out effectively; otherwise investigations and running costs become high. In this paper, we introduce delay reduction measures and indices, which indicate the frequency of delays and the scale of delays.

Keywords: train delay, train timetable, delay measures, train traffic record data, Static Index, Active Index.
\end{abstract}

\section{Introduction}

In Japan, it is said that most railways are punctual. That is generally correct. But in the Tokyo metropolitan area especially, several delays often happen during morning rush hour. This is because a massive number of passengers use trains for commuting. And so, trains and platforms are congested, and delays increase. Most railway companies have received many question and complaints for transportation operation. Japanese people are generally punctual by national character. It is important to take delay reduction measures in Japan. 
One of the most serious problems in Japanese railways in urban area is that small delays very often happen during morning rush hour. In order to operate trains densely, dwell times are planned to be as short as possible. In the Tokyo metropolitan area of Japan, during morning rush hour, 25 to 30 trains run hourly in each direction. For most subway lines, a headway of 2 to 3 minutes is kept under the double track. And it often happens that passengers rush onto a train and objects get caught in the doors, dwell times become longer due to them. This causes delays, and the delays are easily propagated to the subsequent trains.

Another cause is through-service operation between different railway companies. Seven of Tokyo Metro's nine lines offer reciprocal through-service with lines operated by other suburban railway companies. It is very convenient for passengers because they need not transfer to go to the Tokyo metropolitan area. But, if one railway company operates over to another company with a delay, the delay will propagate to the other railway company and the timetable will not return to normal operation for a long time.

Under such circumstances, we had to take measures to reduce delays during the morning rush hour. In order to take delay reduction measures effectively, we use train traffic record date which are the data obtained by a train traffic system and contain actual arrival and departure times of trains, and make indices by them. We have analyzed two aspects of delays, one is dwell times and the other is running times. Index of dwell times is element of static (we call it a Static Index), and index of running times is element of active (we call it an Active Index). So we use these indices and analyze train delays. We show the details of the indices and how to take delay reduction measures on the Tokyo Metro Tozai Line.

\section{Outline of Tozai Line}

The Tozai Line runs between Nakano and Nishi-funabashi Stations and covers $30.8 \mathrm{~km}$ (Figure 1). It is interconnected with JR Line at Nakano Station and with JR line and Toyo Rapid Line at Nishi-funabashi Station. Although Tozai Line is owned by Tokyo Metro, about one half of the track is on the ground.

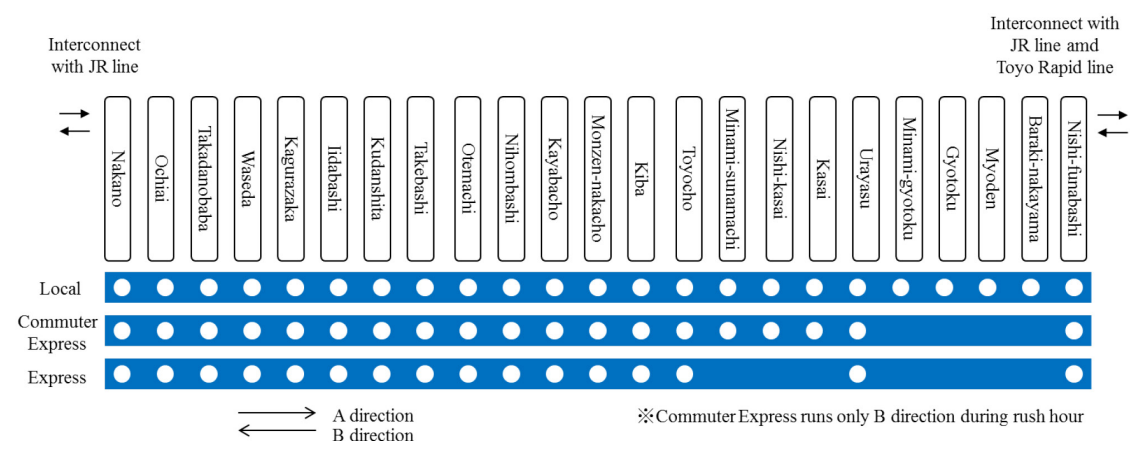

Figure 1: Map of Tozai Line. 
An average daily passenger number hit about 1,322,000 (recorded for 2012 business year). During the morning rush hours, trains from Nishi-funabashi Station toward Nakano Station (we call this direction "B direction"), is more congested. In the most congested section, from Kiba Station to Monzen-nakacho Station, the highest congestion rate of 199 percent was observed in 2011 business year. Tozai Line yields highest congestion rate in the metropolitan area.

\section{Approaches to delay reduction measures and analysis of onset of delay}

The robustness of train schedules has been widely discussed [1]. The discussion could be classified roughly in two categories. One is to improve robustness by means of improving the train schedules themselves $[2,3]$. In order to implement effective measures against delay, delay circumstances should be analyzed and delay factor should be identified. Overall outline of measures against delay is shown in Figure 2. Utilizing the train traffic record data and a chromatic diagram, actual delay state can be visualized. And then utilizing the Static Index of dwell times, that is, the static factor for train operation, and the Active Index of running times between stations, which is, the active factor, the delays were quantified so that a comparison of the degree of influence was made available. Thus, investigations were factors at stations or legs between stations that had great influence on delays. These factor investigations and measures were systematized and implemented for each Factor shown in Figure 2. In this analysis, chosen was a leg between Urayasu Station and Kayabacho Station for an hour in the most congested morning rush hours, with 27 hourly trains having a tendency toward extended delay, on weekdays in June of 2008 (except days of significant accident).

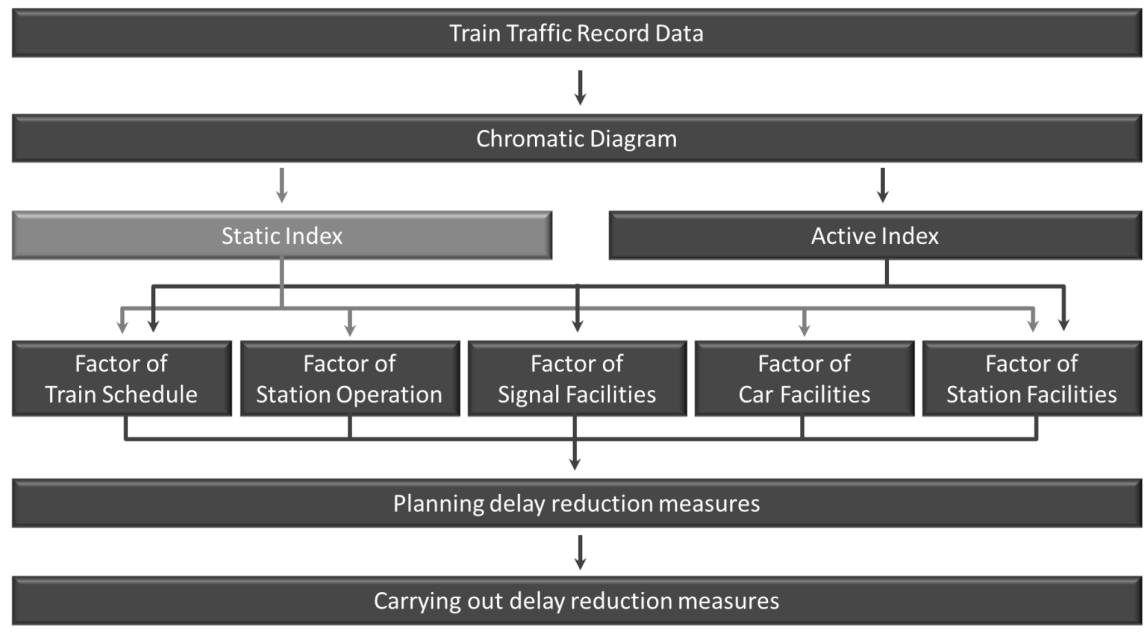

Figure 2: Overall outline of measures against delay. 


\subsection{Visualization of train traffic record data}

It is very important and useful if we can intuitively grasp where and when delays are emerging and how they are propagating to other trains. Figure 3 is what we call a chromatic diagram. This diagram is made from train traffic record data on weekdays in June of 2008 (except days of significant accident). Train traffic record data might be very useful to know how the trains were operated [4-6] and by using appropriate algorithm, we can get useful insight about train operation. For example, in [7], an algorithm to identify a cause of delays using train traffic record data for a long term is presented. Using chromatic diagram, we can know where a delay emerges and how the delay is propagating. Each train segment is colored, reflecting the degree of the delay. If the delay is less than ten seconds, the color is indigo. If the delay is more than one hundred and ninety seconds, the color is red. If the delay is between ten and one hundred and ninety seconds, the color is blue, green, yellow or orange.

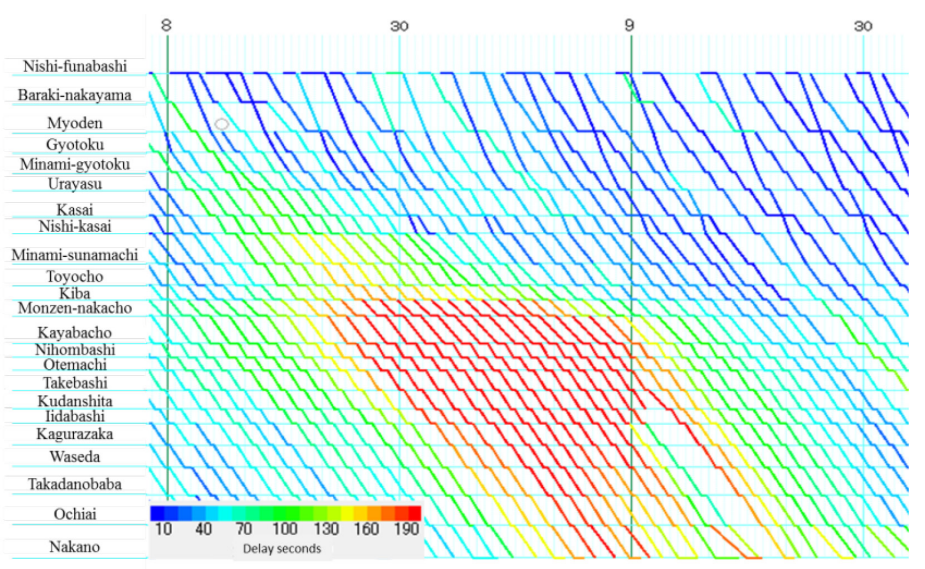

Figure 3: Chromatic diagram on June 2008.

\subsection{Static analyses}

In static analysis, of trains with dwell times exceeding planned ones, we focused on the ones which would pass delays on to subsequent trains. By analyzing how much delays were seen at each station, reasons for delay causing beyond planned dwell times were judged. The interval between trains is constructed by dwell time and minimum headway and buffer time (Figure 4). The minimum headway is decided by signaling system.

To secure transportation capacity in an hour within the most congested morning rush hours, Tozai Line operates $27 \mathrm{train} / \mathrm{h}$ (an average interval of 2 minutes and 18 seconds) in each direction. Based on this scheme, the planned dwell times for every station were established. Figure 5 shows breakdowns of the headway of 2 minutes and 18 seconds for the stations between Urayasu Station, where delay would begin to expand, and Otemachi Station, which is one of the 
key stations for mass transit. The sum of the buffer time and the planned dwell time is the maximum time that can be allowed to a train as its dwell time without propagating delay to a subsequent train. Therefore this time is defined as the acceptable dwell time.

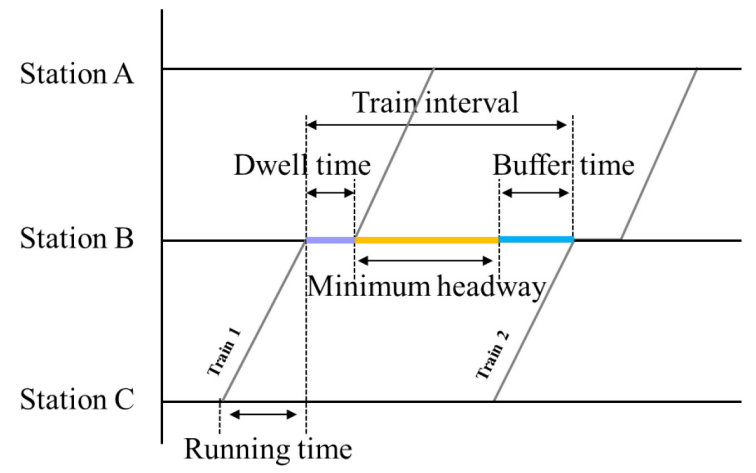

Figure 4: Constitution of train interval and running time.
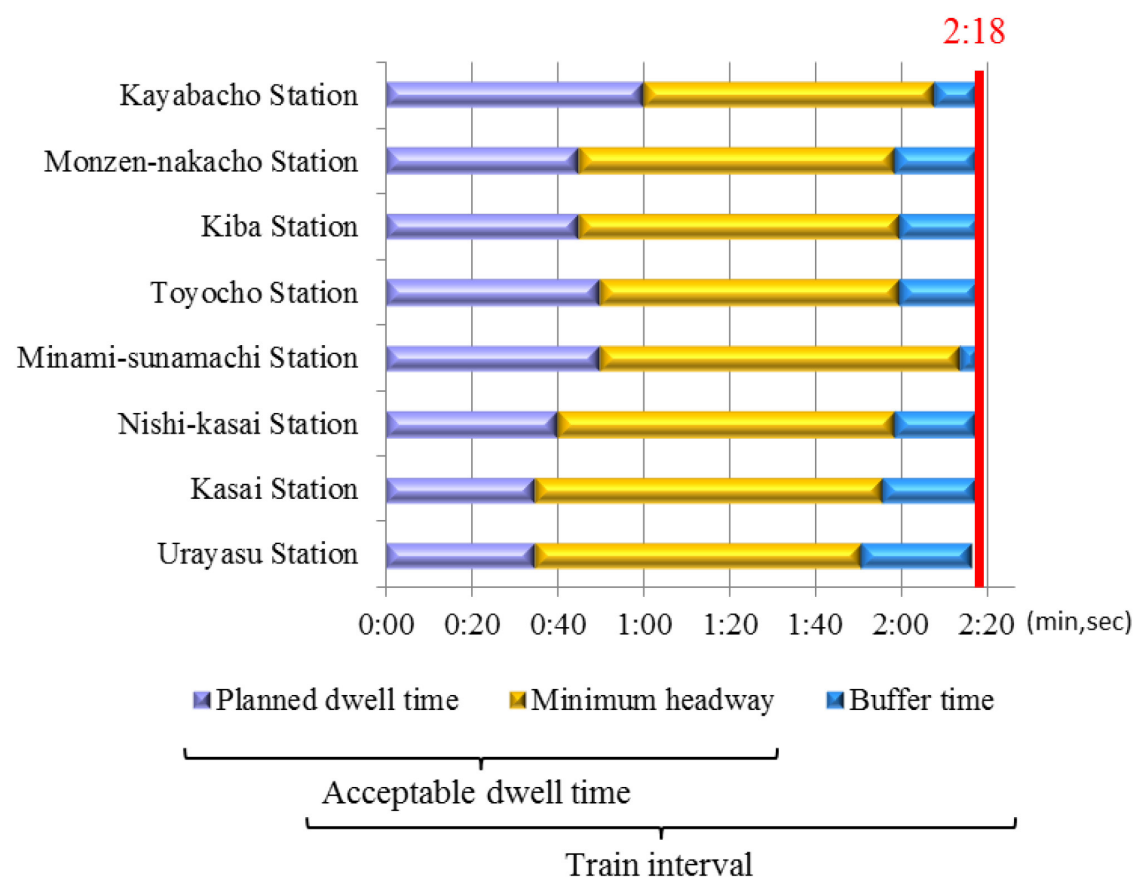

Figure 5: Constitution of train interval at each station. 
As the trains for this analysis passed on delay to subsequent trains, they were regarded as the ones that exceeded the acceptable dwell times. Using those occurrence rates and exceeding amounts, reasons for delay occurrence were guessed. First, exceeding rate of acceptable dwell time is obtained by dividing the number of trains exceeding acceptable dwell times at each station by the number of trains in an hour in the most congested rush hours. These rates together with exceeding averages of acceptable dwell times over the planned will give the situation of exceeding dwell time.

Studying influences of exceeding rates of acceptable dwell times and exceeding averages of acceptable dwell times on delay amounts made it clear that if both numbers are high, influence becomes relatively stronger than at other stations. And the simpler the equations for assessments, the more desirable so that the product of an exceeding rate of acceptable dwell time and an exceeding average of acceptable dwell time over planned dwell time (eqn. (1)) is now adopted as a Static Index (SI value) of exceeding acceptable dwell time at each station.

$$
\begin{aligned}
& \text { SI Value }=\text { Exceeding Rate of Acceptable Dwell Time } \mathrm{x} \\
& \text { Exceeding Average of Acceptable Dwell Time }
\end{aligned}
$$

SI values for each station are shown in Table 1. Thus the comparison of relative magnitudes of exceeding acceptable dwell times at each station has become an effective tool to pick stations where onsite research should be carried out on passenger movements including those flow in getting on and off.

Table 1: SI value at each station.

\begin{tabular}{|l|c|c|c|}
\hline \multicolumn{1}{|c|}{ Stations } & $\begin{array}{c}\text { Exceeding rates } \\
\text { of acceptable dwell times }\end{array}$ & $\begin{array}{c}\text { Exceeding average of } \\
\text { acceptable dwell times }\end{array}$ & SI values \\
\hline Urayasu Station & 0.063 & 7.62 & 0.46 \\
\hline Kasai Station & 0.170 & 7.70 & 1.39 \\
\hline Nishi-kasai Station & 0.138 & 11.02 & 1.60 \\
\hline Minami-sunamachi Station & 0.483 & 8.57 & 4.27 \\
\hline Toyocho Station & 0.231 & 9.65 & 2.27 \\
\hline Kiba Station & 0.154 & 13.54 & 2.20 \\
\hline Monzen-nakacho Station & 0.217 & 8.93 & 2.06 \\
\hline Kayabacho Station & 0.348 & 5.88 & 2.01 \\
\hline
\end{tabular}




\subsection{Active analyses}

For dealing with delay measures, not only the Static Analysis where dwell time at a station is studied but focusing on running time between stations (hereinafter, referred to as Active Analysis) becomes important. A reason for extending the running time between stations is the extended dwell time of the preceding train. Then the train comes close to the preceding train resulting in slowing down or coming even to a standstill somewhere in between stations. If it is possible to get rid of the exceeding dwell time, exceeding running time between stations can also be eliminated at the same time. However, in case of Tozai Line, the dwell times vary from 35 to 60 seconds. Under these circumstances, it is hard to eliminate the exceeding dwell time by controlling passenger flow. Then taking measures simultaneously on running time where the exceeding running time is relatively significant will yield an overall effectiveness.

Paying attention to the portion of the number of trains with exceeding running times in the total number of trains (hereinafter, referred to as exceeding running time between stations rate) and to the average of exceeding running times with regard to the trains operated exceeding the planned running times between stations (hereinafter, referred to as average of exceeding running time between stations), analyses were executed based on the actual data.

Like the Static Analysis, relating to running time between stations, a product of exceeding running times between stations rate and average of exceeding running times between stations is evaluated as it plays a role of an index (Active Index=AI Value, eqn. (2)) that will suggest the magnitude of exceeding running time between stations.

$$
\begin{aligned}
\text { AI Value }= & \text { Exceeding Running Time between Stations Rate } \mathrm{x} \\
& \text { Average of Exceeding Running Time between Stations }
\end{aligned}
$$

The necessity of AI analyses comes from the fact that, as explained previously, there is a limit to suppression of exceeding dwell time leading to unavoidable exceeding running time between stations. And attention should be paid to SI value and AI value: the maximum value of the former is 4.27 seconds (See Table 1) whereas the maximum value of the latter is 37.89 seconds (See Table 2), with AI having delay influence of 8.9 times over SI.

Thus, in addition to SI values, calculating AI values for each running time between stations made it possible to evaluate magnitude of exceeding running times. Based on AI values (See Table 2), causes of exceeding running times between stations were examined for the following legs.

AI values have two inclinations. One is increase from Kasai Station toward Minami-sunamachi Station, and the other is increase from Minami-sunamachi Station toward Kayabacho Station. This means that Minami-snamachi Station and Kayabacho Station forms a bottleneck, and it is likely to influence the exceeding running times between stations of the subsequent trains. 
Table 2: AI value between each station.

\begin{tabular}{|l|c|c|c|}
\hline \multicolumn{1}{|c|}{ Legs Between Stations } & $\begin{array}{c}\text { Exceeding rates } \\
\text { of running times }\end{array}$ & $\begin{array}{c}\text { Exceeding average } \\
\text { of running times }\end{array}$ & AI values \\
\hline $\begin{array}{l}\text { Leg between Urayasu Station and } \\
\text { Kasai Station }\end{array}$ & 0.464 & 13.01 & 6.04 \\
\hline $\begin{array}{l}\text { Leg between Kasai Station and } \\
\text { Nishi-kasai Station }\end{array}$ & 0.677 & 12.50 & 8.46 \\
\hline $\begin{array}{l}\text { Leg between Nishi-kasai Station and } \\
\text { Minami-sunamachi Station }\end{array}$ & 0.720 & 36.69 & 5.67 \\
\hline $\begin{array}{l}\text { Leg between Minami-sunamachi Station and } \\
\text { Toyocho Station }\end{array}$ & 0.295 & 19.19 & 17.44 \\
\hline $\begin{array}{l}\text { Leg between Toyocho Station and } \\
\text { Kiba Station }\end{array}$ & 0.754 & 23.13 & 36.24 \\
\hline $\begin{array}{l}\text { Leg between Kiba Station and } \\
\text { Monzen-nakacho Station }\end{array}$ & 0.889 & 40.77 & 37.89 \\
\hline $\begin{array}{l}\text { Leg between Monzen-nakacho Station and } \\
\text { Kayabacho Station }\end{array}$ & 0.892 & 42.49 & 5.67 \\
\hline
\end{tabular}

\section{Counter measures to improve train delay}

We can grasp where and when delays are emerging by Chromatic diagram, and we can analyse negative effect of delay by SI values and AI values. Based on them, we took effective delay reduction measures on the Tozai Line since fiscal 2008. Implementation of those measures are summarized in Table 3.

Table 3: Summary of delay reduction measures on the Tozai Line.

\begin{tabular}{|l|l|c|}
\hline \multicolumn{1}{|c|}{ Item } & \multicolumn{1}{c|}{ Content } & $\begin{array}{c}\text { Date of } \\
\text { implementation }\end{array}$ \\
\hline $\begin{array}{l}\text { Alteration of Stop Line at Monzen- } \\
\text { nakacho Station } \\
\text { (Factor of Station Facilities) }\end{array}$ & $\begin{array}{l}\text { Alleviation of uneven congestion } \\
\text { Shortening of dwell time }\end{array}$ & $\begin{array}{c}\text { September } \\
2008\end{array}$ \\
\hline $\begin{array}{l}\text { Thoroughgoing operation by Extra } \\
\text { Station Staff at high SI value stations } \\
\text { (Factor of Station Operation) }\end{array}$ & Shortening of dwell time & October 2008 \\
\hline $\begin{array}{l}\text { Installation of Approach Code Signal } \\
\text { at high AI value legs between stations } \\
\text { (Factor of Signal Facilities) }\end{array}$ & $\begin{array}{l}\text { Shortening of running time } \\
\text { Prevention of secondary delay }\end{array}$ & November 2008 \\
\hline $\begin{array}{l}\text { Modification of Train Time table } \\
\text { (Factor of Train Schedule) }\end{array}$ & Optimization of dwell time & March 2009 \\
\hline $\begin{array}{l}\text { Intensive of Trains with wider door car } \\
\text { (Factor of Car Facilities) }\end{array}$ & Shortening of dwell time & $\begin{array}{c}\text { From May } \\
2010 \text { seriatim }\end{array}$ \\
\hline
\end{tabular}

\subsection{Improvement by factor of train schedule}

Train schedule modifications such as extending dwell times to meet actual circumstances could be measures to improve robustness. But haphazard extension of dwell times would damage punctuality and raise a risk to decrease capability to absorb next delays. Thus actual circumstances should be taken into consideration in extending dwell times. 
In some lines of Tokyo Metro, both express trains and local trains are operated. Express trains and the like have tendency to be more congested, leading to prolonged dwell times. Therefore, if we give up operation of express trains during rush hours, misdistribution of passengers will be lessened and excessive dwell times will be prevented.

\subsection{Improvement by factor of station operation}

Especially at stations with high SI values, it often happens that passengers rush onto a train and objects get caught in the doors. Dwell times become longer due to them. Preventing rushing onto a train and door-jamming, facilitating passengers getting on and off or thorough traffic control of passenger flow would shorten dwell time. In some cases, congested stations with high SI values are short of station staff that help shorten dwell times. So those stations should have extra staff.

\subsection{Improvement by factor of signal facilities}

In line with improving robustness at a delay occurrence, it is essential not to propagate it to the subsequent trains. In case of prolonged dwell times forcing subsequent trains to speed down or stop even between stations, degree of delay propagation would depend on how closely the subsequent train could catch up on the preceding train. Under these circumstances, applying an approach code would be powerful measures to hold down delay propagation.

We have now introduced an ATC system which is called "1-step brake control." It is designed in such a way that one time application of 1-step brake control is enough to make the train come to a halt rather than to repeat brake application and release at every signal code. Thus, braking times have been lessened and trains have come to ride well.

However, in case of approaching preceding train under 1-step brake control during dense operation like morning rush hours, entering stop signal area at a low speed will activate 1-step brake. Then the train in question will come to a halt short of a line it may have allowed to reach. Obviously subsequent trains will suffer influence of delay propagation. So effective measures would be to apply an approach code as much as practicable, especially at sections of noticeable train congestion.

\subsection{Improvement by factor of station facilities}

At stations with high SI values, passenger flows near and at narrow passages of staircases and platforms have been big issues.

At Monzen-nakacho Station, in addition to the factor of congestion around the lead car due to transfer to and from the Oedo-Line run by the Tokyo Metropolitan Government, the lead car is for the exclusive use of women so that passengers getting off from second and subsequent cars abode around the narrow passage on the platform prolonging times for getting on and off. To this specific issue, considering the length of the platform and function of the signals, found 
was the possibility to shift the stop line 5 meters forward to eliminate the congestion.

\subsection{Improvement by factor of car facilities}

Static analyses indicated that as to Tozai Line not only forced boarding and door-jamming but also onboard high congestion had a tendency to prolong the time for getting on and off.

As a countermeasure, five trains consisting of cars with wider doors $(1,800 \mathrm{~mm}$ as compared to normal $1,300 \mathrm{~mm})$ were tentatively operated from 1991. Thirteen of those were added in May of 2010 and intensively operated during the morning rush hours.

\section{Effectiveness of improvement}

By implementing delay improving measures, the amended SI and AI values are as shown in Figures 6 and 7.

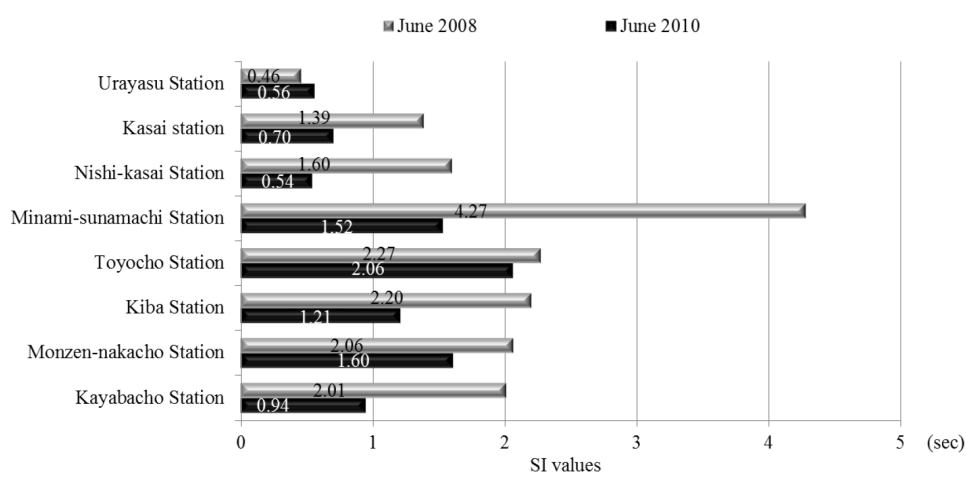

Figure 6: Comparison of SI values.

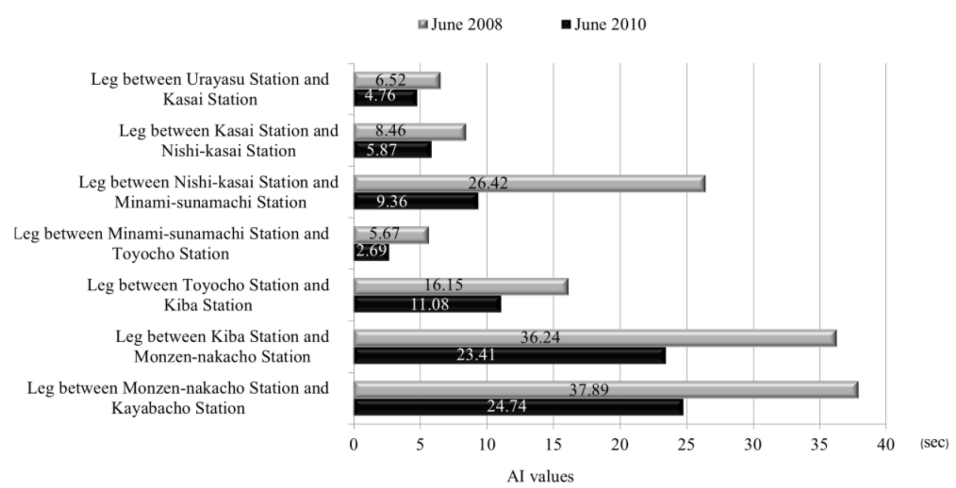

Figure 7: Comparison of AI values. 
First, as to SI values, at Kasai and Nishi-kasai Stations where there are many boarding passengers, and at Kayabacho Station where there are many disembarking passengers, improvement in SI values is observed. This improvement is believed to widely stem from promotion of smooth getting on and off and leading of passenger flow and Factor of Car Facilities, that is, introduction of cars with wide doors. And at Toyo, Kiba and Monzen-nakacho Stations where there are many boarding passengers, it was effective to adopt Factor of Station Operation, that is, promotion of smooth getting on and off and prevention of abiding to form pileup on platform. Especially at Monzen-nakacho Station, together with Factor of Station Facilities, that is, facilitating passenger flow by means of alteration of stop line, great effectiveness was earned. As SI value was low to begin with at Urayasu Station in June of 2008, it remained more or less unchanged.

Next, as to AI values, on the legs between Nishi-kasai and Minamisunamachi Stations and Monzen-nakacho and Kayabacho Stations, installation of approach code signals was greatly effective. As to the leg between Minami-sunamachi and Kayabacho Stations where AI value was high, trains now could come closer to the preceding ones during train congestion between Monzen-nakacho and Kayabacho Stations, which improved AI values for all the intervals between all the adjoining stations. Similarly, for the leg between Nishi-kasai and Minami-sunamachi Stations where an approach code signal was installed, great improvement of AI value was seen, coupled with improved SI value at Minami-sunamachi Station.

Comparison of average delays experienced B direction (operation toward Nakano Station) in June of 2008 and June of 2010 is summarized in Figure 8 and Figure 9. It is seen that delay was much lessened by implementing delay improvement measures referred to above. Comparison by chromatic diagrams is shown in Fig. 20. Red lines representing delay of 190 seconds or longer are seen diminishing drastically. Furthermore, even if delay once occurs, propagation of it toward subsequent trains is small because delays of each train were now slight, and found is early recovery.

\section{Conclusion}

This paper deals with actual train traffic record data which had been difficult to be collected. Delay state was summarized in indices from Static and Active aspects, which paved the approach way to implementation of delay prevention measures. This approach made causes of delay occurrence in Tozai Line clear, so that it was possible to implement effective delay prevention measures and confirmed was its high effectiveness.

By deepening this method, it can be highly versatile tool to prevent delay. Now, for the other lines where delay is an issue, this approach will be applied to suppress delay taking into consideration the features of the line. 


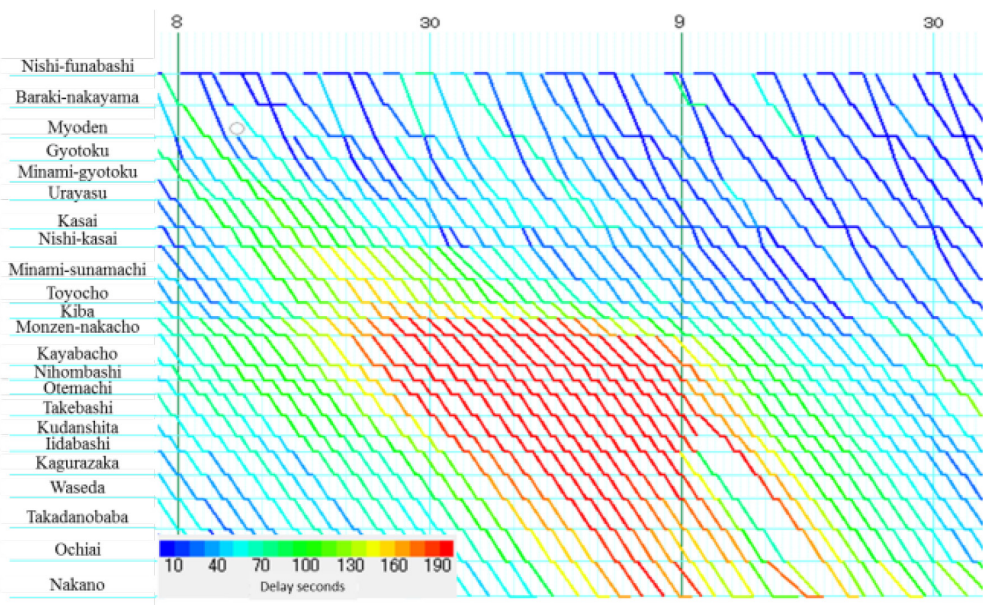

Figure 8: Chromatic diagram on June 2008.

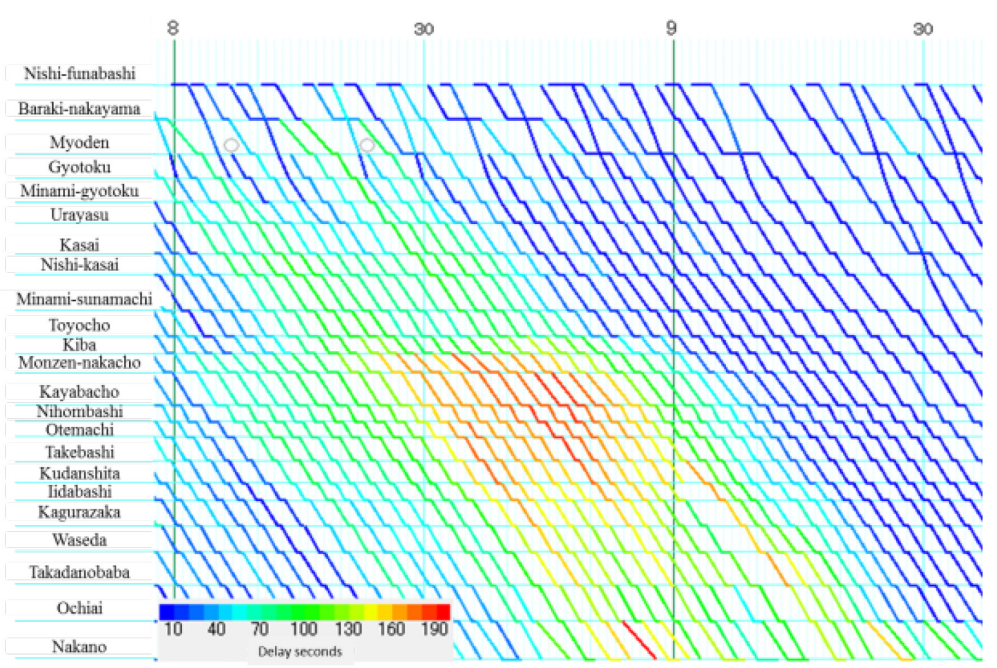

Figure 9: Chromatic diagram on June 2010.

\section{References}

[1] M. Carey: Ex ante heuristic measures of schedule reliability, Transportation Research Part B, Vol. 33, pp. 473-494, 1999.

[2] K. Ushida, S. Makino, N. Tomii Increasing Robustness of Dense Timetables by Visualization of Train Traffic Record Data and Monte Carlo Simulation, WCRR2011 - World Congress On Railway Research, Lille, France, 2011. 
[3] L Kroon, R. Dekker, G. Mar'oti: Stochastic Improvement of Cyclic Railway Timetables, Transportation Research Part B: Methodological, Vol. 42, No. $6,2008$.

[4] D. van der Meer, R. Goverde, I. Hansen: Prediction of train running times and conflicts using track occupation data, WCTR - World Congress on Transportation Research, Lisbon, Portugal, 2010.

[5] T. Graffagnino: Ensuring timetable stability with train traffic data, Computers in Railways XIII, WIT Press, 2012.

[6] A. Yamamura, M. Koresawa, S. Adachi, N. Tomii: How we have succeeded in regaining Punctuality on the Tokyo metropolitan Railway Network, WCRR2013 - World Congress on Railway Research, Sydney, Australia, 2013.

[7] A. Yamamura, M. Koresawa, S. Adachi, N. Tomii: Identification of Cause of Delays in urban Railways, Computers in Railways XIII, WIT Press, 2012. 